\title{
Landscape and Geomorphological Conditions for The Development of Landslides on The Territory of The Chechen Republic
}

\author{
Rustam Gakaev ${ }^{1, *}$, Tumisha Bachaeva ${ }^{2,3}$, Zina Aydamirova ${ }^{4}$ \\ ${ }^{I}$ Chechen State University named after A.A.Kadyrov, Grozny, Russia \\ ${ }^{2}$ Research Institute. H.I.Ibragimova of the Russian Academy of Science, Grozny, Russia \\ ${ }^{3}$ Grozny State Oil Technical University named after Academician M.D. Millionshchikova, Grozny, Russia \\ ${ }^{4}$ LLC «Firm ORGRES», Grozny, Russia \\ *Corresponding author. Email: rustam.geofak@yandex.ru
}

\begin{abstract}
Landslides pose a long-term threat to people and their property and damage the environment in general. Therefore, much effort has been made to assess the risk of landslides and propose mitigation methods based on key characteristics of the landslides, including range and extent, volume, trigger mechanism, recurrence and subsequent evolution. The landslide overview provided by morphological analysis has played a fundamental role in improving the understanding of landslides. Morphological analysis using observation and identification techniques such as contour topographic maps, aerial photography and remote sensing images is considered an important task in the early stages of landslide research.
\end{abstract}

Keywords: landslide research, landscape, territory, morphological features, geographic referencing.

\section{INTRODUCTION}

Landslide processes represent successive changes in the composition, state and properties of a landslide from the moment of its inception and movement to another level up to complete attenuation, manifested in deformations of the rocks composing the landslide. The landslide process occurs as a result of an imbalance of the slope and continues (sometimes in several stages) until a new state of equilibrium is reached. The spread of landslides and the nature of the landslide process are determined by a complex of engineering and geological conditions of the area, among which the most important role is played by lithological-geological, geomorphological, climatic, etc. [1].

Landslide is a general term used to describe the downward movement of soil, rocks and organic materials under the influence of gravity, and the landform resulting from such movement. Gravity affects all objects on Earth. From the largest mountains to the smallest grains of sand, gravity pulls everything towards the center of the planet. Mass movements are the result of shear stresses on slopes (caused by gravity, material weight and groundwater) that overcome the internal resistance of materials (consisting of the cohesive properties of the slope particles and their internal friction) [2].

In general, scientists around the world use many terms to refer to this phenomenon, for example, "landslide", "landslides", "mass movements", "gravitational movements" and "tilting movements" [3].

The morphological features of relatively old landslides are often disturbed by surface processes such as weathering, erosion and vegetation colonization. The limited accuracy of aerial and satellite imagery in many cases prevents detailed analysis of old landslides. The recurrence of landslides is a serious problem in engineering projects as it shows the evolution of the landslide and its potential activity. However, the recurrence of landslides in a specific area cannot be easily and accurately determined, primarily due to the lack of historical data on recent geo-referenced landslides.

Therefore, it is important to study landslides that belong to an earlier period in the evolutionary history 
of the area. Volume estimation is critical to characterize and understand landslides. The volumes of excavation and landslide embankment can be estimated using two digital terrain models (DEM) [4].

DEM information can facilitate identification and assessment of landslide activity and evolution. However, it is relatively difficult to estimate the volume of the old landslide area. The method for determining the volume of the landslide is to reconstruct the paleogeomorphology before the landslide, which requires regional detailed topographic data and reasonable methods of geomorphological reconstruction.

For almost a quarter of a century, many territories of the Republic have practically not been studied in relation to the dynamics of landslide processes. The active development of the territory has led to the need for a more detailed analysis of the factors that lead to the activation of slope processes, which was one of the areas of study by the research laboratory "Landscape Research" [6].

On the territory of the Chechen Republic, highmountain subalpine shrub-meadow landscapes are most susceptible to avalanche danger, mid-mountain forest landscapes are subject to landslide danger, upper mountain forest and post-forest landscapes are most likely to be flooded, deltaic and floodplain landscapes are most likely to be flooded; landscapes.

The importance of anthropogenic landforms is undeniable, but their position in heritage concepts is still a matter of debate. The Convention for the Protection of the World Cultural and Natural Heritage [4] includes some anthropogenic landforms as part of the cultural heritage: "works of man or combined works of nature and man, as well as territories, including archaeological sites, which have outstanding universal value with historical, aesthetic, ethnological or anthropological point of view ". The guidelines for the inclusion of certain types of properties on the World Heritage List [3] also indicate cultural landscapes and heritage channels. Specific anthropogenic landforms can be considered as a fullfledged part of the mountain heritage [2]. This type of heritage is considered a type of cultural heritage. However, the natural aspects of mining operations (geological conditions, type of extracted material), as well as anthropogenic modifications, landforms and processes (for example, silted dams, open cuttings, embankments and embankments, tailing dumps) are also taken into account [4].

A special situation develops in urbanized areas, which are usually highly susceptible to anthropogenic transformations of the relief and, therefore, the number of anthropogenic landforms is high here. In these cases, anthropogenic landforms can be considered as a component of "urban geo-heritage" [5]. These sites are clearly not natural, but they have a strong connection with geological and geomorphological aspects. Geomorphological heritage is defined as a collection of landforms worthy of protection and transmission to future generations. Geomorphological heritage includes not only sensory geomorphological objects, but also cultural (anthropogenic) components, the value of which is determined by geomorphological conditions. In this context, anthropogenic landforms can be viewed as specific examples of geomorphosis [4] and define them as "geomorphological objects or wider landscapes. They can be altered, damaged and even destroyed by human activities, "or they can be" geocultural sites ", which are defined as places where geo-heritage interacts with cultural values. Thus, specific anthropogenic landforms can be estimated using methods similar to those used in the concept of geomorphosis.

\section{MATERIALS AND METHODS}

Geomorphological analysis is one of the most important tasks in the study of landslides; however, this depends on the resolution and quality of the dataset being used. Classical techniques such as aerial photography and stereoscopic analysis have been used to extract detailed characteristics of the target area.

In addition to assessing the hazard of natural processes, which provide a qualitative characteristic, recently, a risk assessment has been used, which gives a quantitative characterization of the hazard. Risk in this article refers to the likelihood of undesirable consequences for the population and economic facilities for various purposes, including settlements, transport communications, linear structures, etc. Among the whole set of indicators of risk assessments in this article, the probable damage per year from the impact of landslides within municipalities (administrative districts) is used as an indicator for assessing the risk of landslides. Currently, there are no statistical economic indicators at the level of municipalities that could be used in risk assessment. There is only statistical information about the gross regional product at the level of krais, oblasts and republics. Therefore, an original method was proposed, which made it possible to characterize the gross regional product at the level of municipal associations.

For the study, we decided to apply a set of criteria based on the methods presented by Pereira and Pereira, as well as by Reinard et al. Both methods have been tested in several studies and have been used on different types of sites, including geocultural ones. Since the assessment is for anthropogenic landforms, minor changes and additions have been made. 
Exclusion of the criterion of "paleogeographic importance" in the framework of scientific values: in the case of anthropogenic landforms, paleogeographic value can be a discriminatory criterion, since specific anthropogenic landforms have appeared recently and therefore have low value in terms of the possibilities of reconstructing the paleogeography of the study area. [5].

- Inclusion of the criterion of "educational value": education and training are an important tool for environmental protection [7]. They play an important role in the development of sustainable forms of tourism, especially geotourism [8], so they should be assessed separately.

- Inclusion of the criterion of "diversity of cultural values": anthropogenic landforms are always associated with cultural aspects (since they are created as a result of human activities or relate to the use of natural resources by people). Initially, the methods allowed only the presence / absence to be assessed and did not reflect the diversity and quantity of these added values and elements, therefore the criterion "cultural diversity" was added.

- Exclusion of the criterion of "aesthetic value": usually this criterion is assessed using visibility, the number of colors or the structuring of the space and is considered relatively subjective [7].

In the case of anthropogenic landforms, this aspect is very difficult to assess due to the diversity of the types of landform origin. The criterion "visibility" partially replaces "aesthetic value".

The study area is located on the territory of mountainous Chechnya [4], and this suggests that there will be a wide variety of landforms. In the northern and central parts, the relief is tectonic (the presence of horsts and grabens and tectonically determined valleys) and is more pronounced; the southern part is rather flat and formed mainly in the Neogene and Quaternary. The uniqueness of Brno's relief lies in the "checkerboard" pattern of ridges and valleys, which influenced the situation with communications, buildings and urban development in general. The relief of the study area is strongly influenced by anthropogenic activities (the presence of numerous urban / residential, communication, industrial, mining and other anthropogenic forms of relief). The use of building materials (loess, sand, building stone - limestone, sandstone, conglomerate, granodiorite, metabasalt) dates back to the 12th century and significantly influenced the landscape [7]. Climatic changes within the middle mountain and steppe landscapes of the Chechen Republic in 19452005 had a tendency to increase precipitation, as well as changes in semi-desert and desert landscapes.

\section{RESULTS}

The high scientific value of our study was attributed to mountainous landforms because of their great diversity in the Chechen Republic (because of these landforms, numerous features of the geosciences could be observed). This was supported by local scientific knowledge (these landforms are often used for geological mapping or have been the subject of specific research, both geoscientific and archaeological) [9]. According to its geomorphological characteristics, the landslide can be divided into zones of depletion and accumulation. Most of the accumulation sites are prone to erosion as a result of subsequent surface processes due to fractured and fragmented weak debris. In contrast, areas of depletion composed of denser bedrock tend to remain stable and easily detectable. Thus, the morphological analysis in this study focused on the depleted areas shown in the UAV and lidar data. Although some small landslides in the study area were identified using satellite imagery or aerial photo analysis, limited resolution and dense vegetation obscured their detailed geomorphic characteristics. Small scarps and depletion depths indicate that these are shallow landslides [10]. Morphological analysis is a key means of identifying landslides. For morphological analysis, satellite images or aerial photographs are traditionally used. A DEM can provide more information about the terrain and is usually created by combining satellite images or aerial photographs. However, the resolution of DEMs obtained from satellite images or aerial photographs is insufficient for highly detailed morphological analysis. For example, dense vegetation in humid areas often obscures some of the morphological features of a landslide; This situation is easily resolved using aerial lidar data and high-resolution imagery. The laser lidar pulse radiation can penetrate the obstacles of various media (trees, clouds and vegetation) based on the corresponding reflections. Images and associated DSMs can create datasets with resolutions ranging from decimeter to centimeter, allowing detailed photointerpretation and analysis of the geologic structure. In this study, DEM data [6].

\section{DISCUSSION}

In addition to the mineralogical characteristics of the rock, the tensile forces in the taphon of genesis are still important: lithostatic and tectonic, causing deformations and ruptures, which thus determine the structural characteristics and lithological heterogeneities, and which will affect the weathering process. The active area is divided into small and numerous active fronts that continue to serve the destruction processes leading to the weathering hive, allowing each unit to evolve independently of the others. The hydrolysis action is of paramount importance and the hydration / exfoliation action is 
due to the cumulative effects of indoor / outdoor thermal and hygrometric deviations. The impact of intense surface evaporation of places in which any tortuosity of the walls creates drops in moisture, accelerates the development of these forms. Earlier, rapid and localized destruction of the formation or rock grain begins, forming two surfaces: an inactive one, which retains the above characteristics of the phenomenon, and an active one, moving into the block, increasing its size.

The overall value must be considered in the context of the specific values of the cultural landscape [8]. A high total cost does not automatically mean that an object is suitable for geotourism and deserves preservation, but it may indicate the need to maintain the current positive status in the Chechen Republic [9]. Likewise, areas of low total value can spark discussion about new opportunities for rational and sustainable use that can add value and reduce uncertainties. One of the methodological approaches is to strengthen environmental measures - they can reduce potential threats to the site, but when there is a conflict of interest or conflicts with urban development, when significant changes or destruction of the site is in the public interest. Another approach is to include threatened sites in so-called rescue geological and geomorphological studies [9] in order to preserve scientific information that can serve educational purposes, even after serious damage or destruction of the object. This research is usually based on a holistic approach that includes humaninduced changes in the biosphere.

\section{CONCLUSION}

Landslide processes represent successive changes in the composition, state and properties of a landslide from the moment of its inception and movement to another level until complete attenuation, manifested in deformations of the rocks that make up the landslide. The landslide process is a piston imbalance of the slope

and continues. The spread of landslides and the nature of the landslide process are determined by a complex of engineering and geological conditions of the area, among which the most important role is played by lithological-geological, geomorphological,
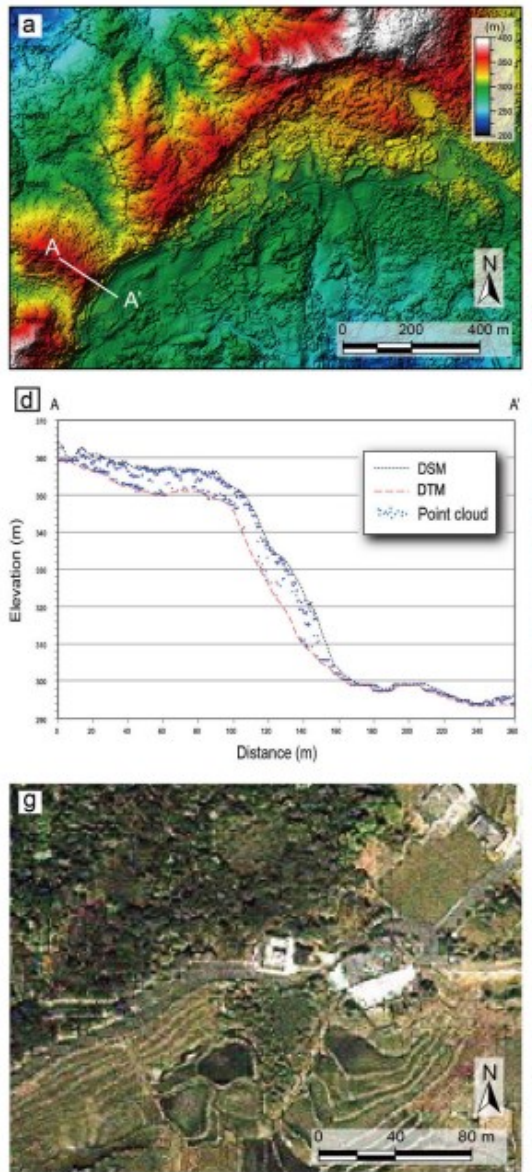
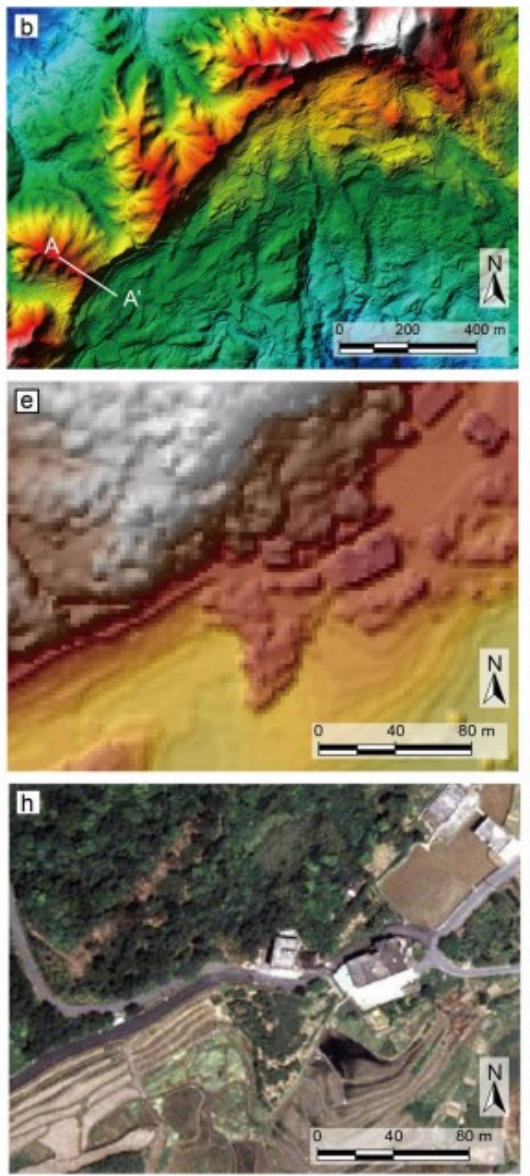
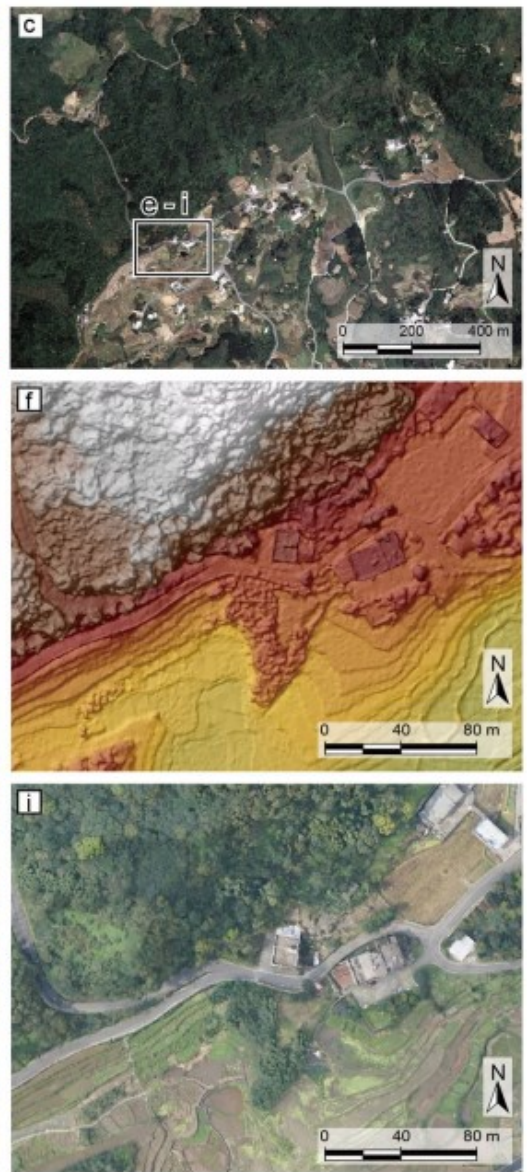

Figure 3 Comparison of images of the same area obtained from different sources. a) Lidar Digital Surface Model (DSM) with a resolution of $2 \mathrm{~m}$; b) lidar digital terrain model (DTM) with a resolution of $2 \mathrm{~m}$; (c) orthorectified aerial photograph, $25 \mathrm{~cm}$ resolution; (d) the difference between the DTM and DSM is the height of the vegetation, while the DTM records the bare ground height as indicated by the lidar point clouds. e) magnification of the DSM lidar with a resolution of $2 \mathrm{~m}$; (f) magnification of the UAS DSM with a resolution of $8 \mathrm{~cm}$; $(\mathrm{g})$ magnification of satellite imagery with a resolution of $1 \mathrm{~m}$; 
climatic, etc.

In the Chechen Republic, landslide processes are widely developed in rocks of all ages and types: from ancient crystalline to loose modern ones. The mosaic, block structure of the territory, the presence of folds expressed in the relief, interbedding of sandstones and limestones with clays, intensively dissected relief, high seismicity, active modern tectonic movements, natural and climatic parameters, and technogenic activity determine the significant development of landslides in terms of distribution and intensity.

The intensification of landslide activity on the territory of the republic is usually associated with periods of abnormally high amounts of precipitation. So, in February - April 1989 in the mountains of the republic there was a catastrophic activation of landslides, covering about 2.5 thousand square meters. $\mathrm{km}$ of territory. The total volume of mudflows reached enormous values: in the area of the settlement of Tsentoroi - 4 million cubic meters. m, Sterch-Kerch 7 million cubic meters. m, Engenoy - 8 million cubic meters. m, Shuani - 10 million cubic meters. m, Pachu - about 23 million cubic meters. m. Of more than 60 settlements in the danger zone, 33 were destroyed, out of 7602 households - 1055 Many kilometers of roads and overhead power lines were destroyed. Almost $15 \%$ of the population living there had to be evacuated from the natural disaster zone [10].

\section{REFERENCES}

[1] V.N. Anisimov, Reasons for the catastrophic activation of landslide processes, 2020, pp.105.

[2] N.I. Alekseevsky, V.N. Mikhailov, Theoretical schemes of channel reshaping and their application in the Terek delta, 2020, pp. 79-91.

[3] L.R. Bekmurzaeva, Sh.Sh. Zaurbekov, Hazardous natural processes in the landscapes of the Chechen Republic, 2009, pp. 138.

[4] A.A. Golovlev, Mountain landscapes of the Chechen Republic and features of their development, 2019, pp. 421.

[5] R.A. Gakaev, Mountain meadow landscapes of the Chechen Republic and features of their distribution, 2019, pp. 149-151.

[6] R.A. Gakaev, I.A. Bayrakov, Geomorphological conditions of landslide formation in the ItumKalinskaya depression of the Chechen Republic, 2018,pp. 92-95.

[7] V.P. Emelyanova, G.N. Danilova, T.Kh. Kolesnikova, Assessment of the quality of land surface waters by hydrochemical indicators, 2020, p. 115 .
[8] A.A. Daukaev, R.Kh. Dadashev, L.S. Gatsaeva, R.A. Gakaev, IOP Conf. Series: Earth and Environmental Science, 2019, p. 378.

[9] R. T.T. Forman, M. Godron, Landscape Ecology, 620 (2010).

[10] E. Reynard, M. Panizza, Geomorphosites: definition, assessment, and mapping. Geomorphol Relief, 177-180 (2018). 